\title{
Immunization With Fc-Based Recombinant Epstein-Barr Virus gp350 Elicits Potent Neutralizing Humoral Immune Response in a BALB/c Mice Model
}

\begin{abstract}
Bingchun Zhao ${ }^{17}$, Xiao Zhang ${ }^{\text {1t, }}$ Claude Krummenacher, 2,3 , Shuo Song ${ }^{4,5}$, Ling Gao', Haojiong Zhang ${ }^{1}$, Miao X ${ }^{1}{ }^{1}$, Lin Feng ${ }^{1}$, Qisheng Feng ${ }^{1}$, Musheng Zeng ${ }^{1}$, Yuting $X u^{6}$ and Yixin Zeng ${ }^{1 *}$
\end{abstract}

OPEN ACCESS

Edited by:

Xu Huji,

Second Military Medical University, China

Reviewed by: Ji Wang,

Harvard Medical School,

United States

Johannes S. Gach,

University of California, Irvine,

United States

*Correspondence:

Yixin Zeng

zengyx@sysucc.org.cn

tThese authors have contributed equally to this work.

Specialty section: This article was submitted to Vaccines and

Molecular Therapeutics, a section of the journal

Frontiers in Immunology

Received: 16 February 2018 Accepted: 16 April 2018

Published: 01 May 2018

Citation:

Zhao B, Zhang X, Krummenacher $C$,

Song $S$, Gao L, Zhang $H, X u M$,

Feng L, Feng $Q$, Zeng $M, X u Y$ and

Zeng $Y$ (2018) Immunization

With Fc-Based Recombinant

Epstein-Barr Virus gp350 Elicits

Potent Neutralizing Humoral Immune

Response in a BALB/C Mice Model.

Front. Immunol. 9:932.

doi: 10.3389/fimmu.2018.00932
' Guangdong Key Laboratory of Nasopharyngeal Carcinoma Diagnosis and Therapy, State Key Laboratory of Oncology in South China, Collaborative Innovation Center for Cancer Medicine, Department of Experimental Research, Sun Yat-Sen University Cancer Center, Guangzhou, China, ${ }^{2}$ Department of Biological Sciences, Rowan University, Glassboro, NJ, United States, ${ }^{3}$ Department of Molecular and Cellular Biosciences, Rowan University, Glassboro, NJ, United States, ${ }^{4}$ State Key Laboratory of Molecular Vaccinology and Molecular Diagnostics, School of Life Sciences, National Institute of Diagnostics and Vaccine Development in Infectious Diseases, Xiamen University, Xiamen, China, ${ }^{5}$ State Key Laboratory of Molecular Vaccinology and Molecular Diagnostics, School of Public Health, National Institute of Diagnostics and Vaccine Development in Infectious Diseases, Xiamen University, Xiamen, China, ${ }^{6}$ Guiyang City National High School, Guiyang, China

Epstein-Barr virus (EBV) was the first human virus proved to be closely associated with tumor development, such as lymphoma, nasopharyngeal carcinoma, and EBVassociated gastric carcinoma. Despite many efforts to develop prophylactic vaccines against EBV infection and diseases, no candidates have succeeded in effectively blocking EBV infection in clinical trials. Previous investigations showed that EBV gp350 plays a pivotal role in the infection of B-lymphocytes. Nevertheless, using monomeric gp350 proteins as antigens has not been effective in preventing infection. Multimeric forms of the antigen are more potently immunogenic than monomers; however, the multimerization elements used in previous constructs are not approved for human clinical trials. To prepare a much-needed EBV prophylactic vaccine that is potent, safe, and applicable, we constructed an Fc-based form of gp350 to serve as a dimeric antigen. Here, we show that the Fc-based gp350 antigen exhibits dramatically enhanced immunogenicity compared with wild-type gp350 protein. The complete or partial gp350 ectodomain was fused with the mouse IgG2a Fc domain. Fusion with the Fc domain did not impair gp350 folding, binding to a conformation-dependent neutralizing antibody ( $\mathrm{nAb}$ ) and binding to its receptor by enzyme-linked immunosorbent assay and surface plasmon resonance. Specific antibody titers against gp350 were notably enhanced by immunization with gp350-Fc dimers compared with gp350 monomers. Furthermore, immunization with gp350-Fc fusion proteins elicited potent nAbs against EBV. Our data strongly suggest that an EBV gp350 vaccine based on Fc fusion proteins may be an efficient candidate to prevent EBV infection in clinical applications.

Keywords: Epstein-Barr virus, envelope protein, gp350, Fc-based vaccine, neutralizing antibody, intranasal immunization 


\section{INTRODUCTION}

Epstein-Barr virus (EBV), known as human herpesvirus 4, is a highly prevalent virus from the Herpesviridae $\gamma$ subfamily (1). EBV is the first virus reported to cause tumorigenesis in infected humans (1-3). It is widely spread among human populations, and over $95 \%$ of adults carry latent EBV worldwide $(4,5)$. EBV establishes lifelong latency in infected individuals. Three types of latencies have been described based on the subset of genes expressed in latently infected cells (6). The latent status of EBV is closely linked to the development and progression of many diseases, such as infectious mononucleosis (IM), nasopharyngeal carcinoma (NPC), posttransplant lymphoproliferative disease, EBV-related gastric carcinoma, and Hodgkin lymphoma (7-14). In some southern provinces of China, where NPC is frequent, it has the highest fatality rate among malignancies. Thus, EBVassociated diseases are an important public health concern. In addition, latent EBV infection was recently shown to accelerate the decay of childhood measles and rubella vaccine responses (15). However, at present no EBV vaccine is available. Development of a successful EBV vaccine is difficult due to (i) the lack of appropriate animal models for evaluation of infection, (ii) the poor protection of previous vaccine candidates, and (iii) inadequate investment in vaccine development (16-18).

To initiate EBV infection, several viral envelope glycoproteins are involved in entry into target cells such as epithelial cells or B-lymphocytes $(19,20)$. Out of these glycoproteins, gp350 is generally considered to be involved in the infection of B-lymphocytes (21). Two cellular receptors, CR2/CD21 and CD35, bind gp350 during entry. The crystal structure of gp350 ectodomain (residues 1-470) showed that about 14 large glycan chains cover the whole surface of gp350 except for the area, which is responsible for binding to CR2/CD21 (22). Despite being the most abundant EBV glycoprotein on virions (23), this glycosylation pattern suggests that native gp350 remains monomeric since its important glycan coverage may prevent protein-protein interaction on the viral envelope (22). Importantly, a monoclonal antibody (mAb72A1), which was raised against gp350, effectively blocks EBV infection of B cells (24-27). Hence, gp350 has been the primary antigen used in the development of EBV prophylactic vaccines (17). Initially, Epstein et al. reported that using purified gp350 as antigen can protect cotton marmosets from developing lymphoma caused by EBV infection (28). In some cases, the immune sera could block infection although neutralizing antibodies (nAbs) were rarely found. This observation implied that most antibodies against purified gp350 probably clear the virus through ADCC or T cell responses (29-31). Polymerization of gp350 on the surface of ferritin nanoparticles significantly increased antigenicity and protected mice against infection by a recombinant vaccinia virus expressing EBV gp350 (32). Candidate vaccines based on gp350 have been tested in clinical trials. Recombinant vaccinia vectors expressing gp350 elicited nAbs against EBV (33). More recently, a recombinant gp350 antigen induced protection from EBV infection in a Phase I/II clinical trial (34). Despite these results, none of these trials have yet reached the final stage of vaccine development. Interestingly, in a Phase II trial performed with seronegative individuals, IM incidence was notably decreased, but EBV infection could not be blocked (35). Besides, recombinant gp350 did not induce nAbs in a cohort of children awaiting kidney transplants, even though the specific antibody titer increased soon after immunization (36).

In Fc-based fusion antigens, the Fc domain of immunoglobulins is fused with the desired protein, which allows the dimerization of the protein and often potently increases its biological and pharmacological characteristics (37-39). The fusion with the Fc domain can remarkably increase plasma half-life and immunogenicity of recombinant antigens. This appears to be due to the combination of a high affinity for the neonatal Fc receptor (FcRn) and a slower clearance due to higher molecular weight (40-42). Besides, the Fc fusion proteins can be easily purified through protein A/G affinity chromatography. Furthermore, the safety of use of Fc in fusion proteins in humans has been clearly established during the development of Fc-based protein drugs and therapeutic mAbs $(37,43)$. For all these reasons, we believe that an Fc fusion approach is a valid way to improve EBV g350 antigen immunogenicity and efficacy as a prophylactic vaccine.

In this study, we expressed two forms of recombinant EBV gp350 ectodomain fused with the Fc domain of mouse IgG2a (mIgG2a-Fc) in insect cells. We used the N-terminal three domains of gp350 (gp350-ECD ${ }_{123}$ ) or the full-length gp350 ectodomain (gp350-ECD $\mathrm{FL}_{\mathrm{FL}}$ ). We found that the fusion with $\mathrm{Fc}$ did not affect the neutralizing epitope recognized by mAb72A1 or the CR2/CD21 binding site of gp350. The immunogenicity of gp350-ECD ${ }_{123}$ and gp350-ECD $\mathrm{FL}_{\text {with }}$ and without Fc fusion was compared in $\mathrm{BALB} / \mathrm{c}$ mice. Infection neutralization assays and antibody-dependent competition indicated that recombinant gp350 fused with Fc domain elicited more potent nAbs compared with non-fusion monomeric gp350 proteins.

\section{MATERIALS AND METHODS}

\section{Construction of Recombinant Bacmids With Insertion of gp350 Ectodomain Fused With mlgG2a-Fc}

Two variants of EBV gp350 ectodomain, gp350-ECD 123 (residues $1-425$, corresponding to the first three $\mathrm{N}$-terminal domains) and gp350-ECD $D_{\mathrm{FL}}$ (residues 1-803, corresponding to the full-length ectodomain) were used. The corresponding sequences from strain M81 were obtained by PCR amplification using specific primers: gp350-ECD ${ }_{123}$-BamH I-F (5'-CGCGGATCCGCCAC CATGGTAAGCGCTATTGTTTTATATGTGCTTTTGGCGG CGGCGGCGCATTCTGCCTTTGCGATGGAGGCAG CCTTGCTTGTG-3') and gp350-ECD 123 -Sal I-R (5'-ACGCGTC GACGGGTGCCTTGGAGAATATAACCTTGTG-3') for gp350$\mathrm{ECD}_{123}$, gp350-ECD $\mathrm{FL}_{\mathrm{FL}}$-BamH I-F (5'-CGC GGATCCGCCACC ATGGTAAGCGCTATTGTTTTATATGTGCTTTTGGCG GCGGCGGCGCATTCTGCCTTTGCGATGGAGGCA GCCTTGCTTGT-3') and gp350-ECD ${ }_{\mathrm{FL}}$-Sal I-R (5'-ACGCGT CGAC GGAGAGGTTTGAGAATCTGG-3') for gp350-ECD ${ }_{\mathrm{fL}}$. These two fragments were inserted into the pFastBacl vector (Invitrogen) by BamH I/Sal I digestion. To guide the secretion of the Fc fusion proteins and obtain correct glycosylation, the coding sequence of gp64 signal peptide was added at the $5^{\prime}$ end of the gp350 fragment by inclusion in the primers. The coding 
fragment of mIgG2a-Fc was synthesized as previously reported (44) and added to the $3^{\prime}$ end of the gp350 fragments by Sal I/Xba I digestion. The soluble gp $350-\mathrm{ECD}_{123}$ was constructed by adding a C-terminal hexa-histidine tag, and an N-terminal gp64 signal peptide fragment included in the PCR primers. The resulting constructs are shown in Figure 1A.

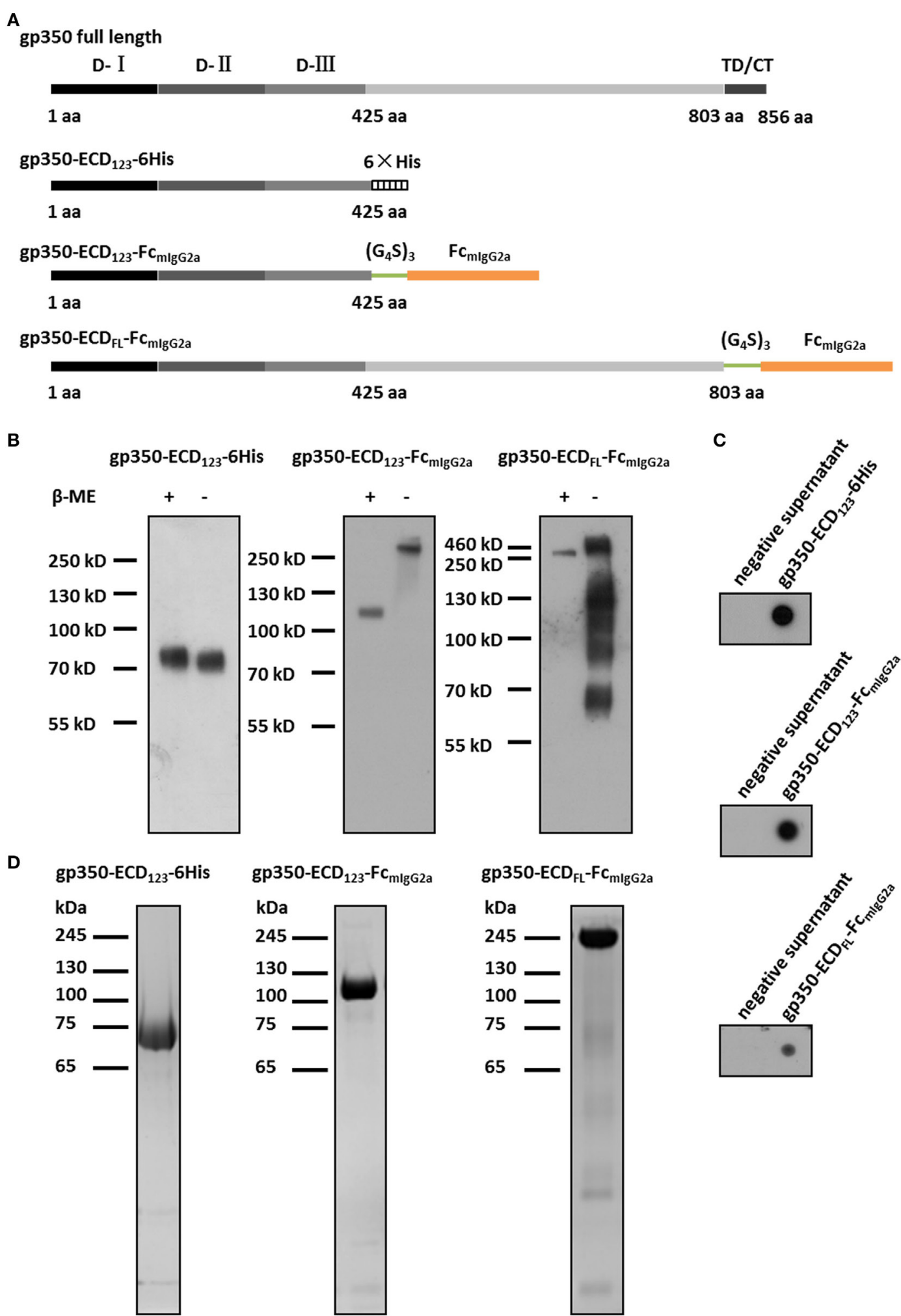


FIGURE 1 | Characterization of Fc-based recombinant gp350 proteins. (A) Diagrams for design of Fc-based recombinant gp350 proteins. The extracellular domains (D-I, D-II, and D-III), transmembrane domains, and cytoplasmic tail (TD/CT) are shown in gray. The 6-histidine tag is shown as a hatched box, the mouse IgG2a Fc domain is shown orange, and the glycine-serine $\left(\mathrm{G}_{4} \mathrm{~S}\right)_{3}$ linker is colored green. (B) Western blot of secreted recombinant gp350 constructs under reducing $(+\beta-\mathrm{ME})$ and non-reducing conditions ( $-\beta-\mathrm{ME})$. gp350-ECD ${ }_{123}-6 \mathrm{His}$ was detected by an anti-His tag antibody, and proteins fused with FC domain were detected with an anti-mouse Fc antibody. For each fusion protein, the same volume (15 $\mu$ l) of supernatants from identical passage 1 baculovirus stocks was loaded onto the gels under reducing and non-reducing conditions. Samples were resolved on 10\% SDS-PAGE. (C) Detection of the indicated recombinant gp350 forms by conformation-dependent anti-gp350 mAb72A1 antibody in the supernatant of bacmid-transfected Sf9 cells using dot blot. Cell culture supernatants from mock-transfected cells were included as negative controls. (D) SDS-PAGE analysis of SEC-purified forms of recombinant gp350. Proteins from the peak fractions were resolved on $10 \%$ gel under reducing condition and stained with Coomassie brilliant blue.

The recombinant bacmids containing the coding fragments of $\mathrm{mIgG} 2 \mathrm{a}-\mathrm{Fc}$ fusion protein were constructed according to the manufacturer's manual. Briefly, DH10B cells were transformed by heat shock with each plasmid constructs. The DH10B cells with positive recombinant bacmids were isolated as white colonies on LB agar plates containing kanamycin, gentamicin, tetracycline, Bluo-gal, and IPTG. Positive colonies were validated by restreaking and the presence of genes encoding fusion proteins was verified by PCR using pUC/M13 Forward and Reverse primers. Finally, the recombinant bacmids were extracted by alkaline lysis, dissolved in TE buffer, and stored at $-20^{\circ} \mathrm{C}$ for subsequent transfection.

\section{Expression and Purification of Fc Fusion Proteins}

The expression of Fc fusion proteins in insect cells followed the bac-to-bac manual of Invitrogen. Briefly, $\sim 8 \times 10^{5}$ Sf 9 cells per well were seeded in a 6-well plate and cultured in monolayers in Sf900-III media (Invitrogen) and transfected with recombinant bacmids using Cellfectin reagents (Invitrogen). Expression was validated in passage 1 (P1) baculovirus stocks after 7-10 days by Western blot. The P1 baculoviruses were subjected to two rounds of plaque selection to obtain positive pure recombinant viruses. For protein expression, P1 recombinant viruses were subjected to two cycles of amplification in High 5 cells cultured in suspension in ESF921 medium (Expression system). High 5 cells were seeded at $0.5 \times 10^{6}$ cells $/ \mathrm{ml}$ and infected with recombinant viruses when the cell density reached $1.5-2.0 \times 10^{6}$ cells $/ \mathrm{ml}$. The multiplicity of infection and infection time were optimized for each recombinant fusion protein to maximize protein expression levels. Culture supernatants containing recombinant proteins were harvested 4-5 days posttransfection, and cell debris was removed by centrifugation and $0.45 \mu \mathrm{m}$ filtration.

All culture supernatants were concentrated 10-fold using Mini Pellicon TFF system (Millipore). Soluble gp350-ECD ${ }_{123}-6$ His was purified using HisTrap FF prepacked column (GE Healthcare) with a GE Akta purifier chromatography system. The concentrated supernatants were dialyzed against equilibration buffer (20 mM Tris- $\mathrm{HCl}, 300 \mathrm{mM} \mathrm{NaCl}, 10 \mathrm{mM}$ imidazole, $\mathrm{pH}$ 7.5), and the HisTrap column was equilibrated with 5-10 column volumes of equilibration buffer. The dialyzed supernatants were applied on the column, which was washed with equilibration buffer until the absorbance reached baseline. Elution was performed using at least five column volumes of elution buffer $(20 \mathrm{mM}$ Tris- $\mathrm{HCl}$, $300 \mathrm{mM} \mathrm{NaCl}, 60 \mathrm{mM}$ imidazole, $\mathrm{pH}$ 7.5). For purification of Fc fusion proteins, the concentrated supernatants were loaded on the pre-equilibrated HiTrap Mabselect column (GE Healthcare) after dialyzed against $1 \times$ PBS. The bound fusion proteins were eluted using $100 \mathrm{mM}$ sodium citrate, $\mathrm{pH} 3.0$, and neutralized with $1 \mathrm{M}$ Tris-HCl, pH 9.5 (300 $\mu$ l Tris- $\mathrm{HCl}$ buffer per $1 \mathrm{ml}$ elution). All the eluted proteins were subjected to SDS-PAGE and Coomassie staining for purity check.

The purified proteins were immediately dialyzed against $1 \times$ PBS and loaded on a Superdex200 increase 10/300 GL prepacked column (GE Healthcare) for further purification. Generally, the samples were concentrated four to five times for loading, and the flow rate was set to $0.5 \mathrm{ml} / \mathrm{min}$. The protein absorbance was monitored at $280 \mathrm{~nm}$. The eluted fractions were checked for purity of fusion proteins using SDS-PAGE, pooled together, and protein concentration was determined using BCA assay kit (Thermo Scientific Pierce) after concentration. Finally, the fusion proteins were aliquoted and stored at $-80^{\circ} \mathrm{C}$.

\section{Construction and Purification of Human CR2 (SCR1-2) Fused With MBP Tag}

The construction and purification of human CR2 (SCR1-2) fusion protein was performed as described previously (45). Briefly, coding sequence corresponding to residues 1-133 of wild-type human CR2 (SCR1-2) was synthesized and inserted into pMALp5x (New England BioLabs) by digestion and ligation steps. The positive plasmid was introduced into BL21 bacteria for protein expression. Crude bacterial lysates were filtered and loaded on the MBPTrap HP column (GE Healthcare). The fusion proteins were eluted using $10 \mathrm{mM}$ maltose in equilibration buffer. Finally, MBPhCR2 SCR1-2 proteins were purified further using size exclusion chromatography described earlier after dialyzed against $1 \times$ PBS and aliquoted to store at $-80^{\circ} \mathrm{C}$.

\section{SDS-PAGE and Immunoblot}

Sodium dodecyl sulfate-polyacrylamide gel electrophoresis (SDS-PAGE) was performed on 10 or 4-12\% gradient acrylamide gels. Generally, gels were ran for $1 \mathrm{~h}$ at $160 \mathrm{~V}$. Total proteins were visualized by Coomassie brilliant blue staining for $1 \mathrm{~h}$ and destained until the background became transparent.

For immunoblotting, after SDS-PAGE, proteins were transferred onto polyvinylidene fluoride membrane (Millipore) for $2 \mathrm{~h}$ $30 \mathrm{~min}$ at $300 \mathrm{~mA}$. Membranes were blocked in 5\% non-fat milk (dissolved in TBST buffer containing $25 \mathrm{mM}$ Tris, $250 \mathrm{mM} \mathrm{NaCl}$, $0.1 \%$ Tween-20, $\mathrm{pH} 7.4$ ) for at least $2 \mathrm{~h}$ at room temperature. For detection of soluble gp350-ECD ${ }_{123}-6 \mathrm{His}$, primary mouse anti-His antibody (Abmart) was diluted 1:2,000 and incubated with membrane at $4^{\circ} \mathrm{C}$ overnight following incubation with secondary goat anti-mouse antibody (1:20,000, Promega) conjugated to horseradish peroxidase (HRP) for $1 \mathrm{~h}$ at room temperature. 
For detection of Fc fusion proteins, the membranes were incubated directly with secondary goat anti-mouse antibody $(1: 20,000)$ for detection using ECL substrate (Advansta).

\section{Mouse Immunization}

Five BALB/c female mice (6-8 weeks old) for each group were immunized with antigens intraperitoneally (i.p.) or intranasally (i.n.). For i.p. immunization, fusion proteins were adsorbed to Imject Alum adjuvant (Invitrogen) according to the manufacturer's instructions, and two doses were tested, 1 or $20 \mu \mathrm{g}$. Primary immunization was performed after collection of preimmune sera at week 0 and followed by one boost at week 3. For i.n. immunization, $20 \mu \mathrm{g}$ antigens (per mouse) was mixed with $25 \mu \mathrm{g}$ CpG1826 (InvivoGen) and dissolved in $1 \times$ PBS, and the final volume was brought to $30 \mu \mathrm{l}$. Mice were immunized at weeks 0 and 2 after sedation induced by injection of $150 \mu \mathrm{l} 5 \%$ chloral hydrate in PBS. Serum samples were collected after $0-5$ weeks.

All mice were purchased from Beijing Vital River Laboratory Animal Technology Co., Ltd. (the joint venture of Charles River Laboratories in China). This study was carried out in accordance with the recommendations of the Institutional Animal Care and Use Committee at the Sun Yat-Sen University Cancer Center. The protocol was approved by the Institutional Animal Care and Use Committee at the Sun Yat-Sen University Cancer Center, and the animals were cared for in accordance with the institutional guidelines.

\section{Enzyme-Linked Immunosorbent Assay (ELISA)}

For determination of serum titers, 96-well ELISA plates (Corning) were coated with soluble gp350-ECD ${ }_{123}-6 \mathrm{His}$ (100 ng in $100 \mu \mathrm{lPBS}$ per well) at $37^{\circ} \mathrm{C}$ for $2 \mathrm{~h}$. After one wash, the plates were blocked using $1 \times$ ED buffer $(0.5 \%$ casein sodium salt, $2 \%$ gelatin, $0.1 \%$ proclin-300, dissolved in $1 \times$ PBS) at $4^{\circ} \mathrm{C}$ overnight. Six 5-fold serial dilutions of serum samples were loaded on the plates (starting with dilution $1 / 100$ ), and incubated for $1 \mathrm{~h}$ at $37^{\circ} \mathrm{C}$, then washed with wash buffer. Secondary anti-mouse antibody conjugated with HRP (Promega) was diluted 1/20,000 and incubated for $45 \mathrm{~min}$ at $37^{\circ} \mathrm{C}$. The signals were developed using EL-TMB kit (Sangon Biotech). Absorbance values at $450 \mathrm{~nm}$ were recorded, and the cutoff determined by OD values of pre-sera which was subtracted from experimental groups was set to 0.1 . To determine the titers of gp350-specific Ig isotypes, the procedure was performed as before (46). Briefly, ELISA plates were coated with gp350-ECD ${ }_{123}$ as described earlier and incubated with diluted sera samples. Then, the Ig isotypes were detected using HRP-conjugated goat antimouse IgG1, IgG2a, IgG2b, IgG3, and IgA (1/10,000, Promega).

For competitive ELISA, mAb72A1 was directly conjugated with HRP using the HRP labeling kit (Proteintech). To quantify binding with mAb72A1-HRP, twofold serial dilution (starting at $1 / 100$ ) were loaded on the plates coated with soluble gp350$\mathrm{ECD}_{123}-6 \mathrm{His}$. The antibody dilution yielding an absorbance of 1.0 (i.e., 1/25,600) was chosen for competition tests. For competition, twofold serial dilutions of serum samples (starting at $1 / 50$ ) were loaded on antigen-coated ELISA plates and incubated at $37^{\circ} \mathrm{C}$ for $1 \mathrm{~h}$. Then, mAb72A1-HRP (dilution $1 / 25,600$ ) was loaded on the plate and incubated at $37^{\circ} \mathrm{C}$ for $30 \mathrm{~min}$, followed by signal development using the EL-TMB kit (Sangon Biotech). The competitive ability of serum samples against mAb72A1 was calculated using this equation: Percent of Inhibition $\%=\left[\mathrm{OD}_{(- \text {serum samples/ }+72 \mathrm{Al})}-\mathrm{OD}_{(+ \text {serum samples } /+72 \mathrm{Al})}\right] / \mathrm{OD}_{(}$

To characterize the binding of mAb72A1 to various gp350 fusion proteins, the fusion proteins were coated on the ELISA plates as described earlier. 24 twofold dilutions of mAb72A1-HRP were added and incubated with gp350 fusion proteins at $37^{\circ} \mathrm{C}$ for 45 min developed using EL-TMB kit.

To detect the binding with MBP-hCR2 SCR1-2, ELISA was performed as previously reported (45).

\section{Determination of Molecular Weight Using Analytical Ultracentrifugation (AUC) Analysis}

Sedimentation velocity experiments were used to determine the $S$ value and molecular weight of the purified recombinant protein samples at $20^{\circ} \mathrm{C}$ on a Beckman XL-A analytical ultracentrifuge equipped with absorbance optics and an An60-Ti rotor. The samples were diluted to $1 \mathrm{OD}$ at $280 \mathrm{~nm}$. PBS was used as the reference buffer. The rotor speed was set at 35,000 rpm for these samples. The sedimentation coefficient was obtained using the c(s) method with the Sedfit software, which was kindly provided by Dr. P. Schuck at the National Institutes of Health (http://www. analyticalultracentrifugation.com). And the molecular weight was calculated using the $c(M)$ module of the Sedfit software.

\section{Surface Plasmon Resonance (SPR)}

Surface plasmon resonance-based antibody competition was conducted on a Biacore T200 instrument (GE Healthcare) as described previously (32). Briefly, soluble gp350-ECD ${ }_{123}-6$ His was immobilized on the CM5 sensor chip (GE Healthcare) by amine coupling at $\mathrm{pH} 5.5$ until the response unit (RU) value reached $\sim 500$. Then, $50 \mu \mathrm{l}$ of the serum samples ( $1 / 40$ dilution) was injected at $30 \mu \mathrm{l} / \mathrm{min}$, and the RU values were recorded as RU of serum. The chip was regenerated by one injection $(50 \mu \mathrm{l})$ of $3 \mathrm{M} \mathrm{MgCl}_{2}$. Then, $50 \mu \mathrm{l}(100 \mu \mathrm{g} / \mathrm{ml})$ of mAb72A1 was injected at $30 \mu \mathrm{l} / \mathrm{min}$ before injecting of serum samples, and subsequently, the chip was regenerated by $\mathrm{MgCl}_{2}$. The $\mathrm{RU}$ values were documented as RU of mAb72A1. Competitive binding ability of serum samples to gp350 was calculated by an equation: Competitive percentage $\%=($ RU of sera - RU of mAb72A1) $/$ RU of sera.

For affinity kinetics analysis between recombinant gp350 and mAb72A1 or MBP-hCR2 SCR1-2, the three recombinant gp350s were immobilized on the CM5 sensor chip (GE Healthcare) at pH 5.5 with low RU value to avoid avidity effect. Then, mAb72A1 or MBP-hCR2 SCR1-2 was injected at $30 \mu \mathrm{l} / \mathrm{min}$, and the chip was regenerated by $10 \mathrm{mM}$ glycine- $\mathrm{HCl}, \mathrm{pH} 1.5$. Surface boundkinetics fit (1:1 fit) was applied for data analysis, and $\chi^{2}$ less than $10 \%$ of $R_{\max }$ value was considered good.

\section{Infection Blocking Assay}

To test the sera's ability to block EBV infection of B-lymphocytes, an infection blocking assay was performed according to previous reports (24). Briefly, $\mathrm{EBV}_{\mathrm{GFP}}$ was prepared using virus producing 
cell line, CNE2-EBV ${ }_{\text {GFP }}$ carrying Akata-EBV-GFP, and aliquoted $100 \mu \mathrm{l}$ per tube. Immunized sera or mAb72A1 were mixed gently with $100 \mu \mathrm{EBV}$ in $1.5 \mathrm{ml}$ Eppendorf tube and incubated for $1 \mathrm{~h}$ at room temperature. Then, $\sim 1 \times 10^{5}$ Akata negative cells (without latent $\mathrm{EBV}$ ) were suspended with the mixture of antibodies and virus and incubated for $3 \mathrm{~h}$ at $37^{\circ} \mathrm{C}$. Following the incubation, the cells were pelleted by centrifugation and washed once using $1 \mathrm{ml}$ PBS. Then, cells were grown in $1 \mathrm{ml}$ RPMI1640 plus $10 \%$ FBS in 12-well plates for 2 days. Uninfected cells incubated with RPMI1640 media were used as negative controls, and cells incubated with EBV, in the absence of immune serum, were included as positive controls.

After 2 days, the cells were collected and washed once with PBS. The EBV infection rate was determined using FACS analysis.

\section{Statistics}

All statistical analyses were conducted with GraphPad Prism version 5. $p$-Values were generated by one-way ANOVA unless specified otherwise. $p$-Values of $\leq 0.05$ were considered statistically significant.

\section{RESULTS}

\section{Construction and Production of Secreted Fc Fusion Proteins}

The fusion with Fc domain of immunoglobulin (IgG) has been shown to dramatically enhance the immunogenicity of antigens due to dimerization and high affinity for $\operatorname{FcRn}(37,47)$. To enhance the immunogenicity and protection potential of EBV gp350, we generated two new Fc-based constructs. The first construct contains the gp350-ECD ${ }_{123}$ domains with the mIgG2a$\mathrm{Fc}$ domain at its C-terminus. These two domains are separated by a $\left(\mathrm{Gly}_{4} \mathrm{Ser}\right)_{3}$ linker to ensure correct protein folding and function (Figure 1A). Since the immunogenicity of the fulllength ectodomain of gp350 in the context of a fusion protein is not well characterized, we designed an Fc-based construct with gp350-ECD $\mathrm{FL}$. The gp64 signal peptide was introduced at the N-terminus for protein secretion, and a Kozak sequence (GCCACC) was included to enhance transcription. For purification of soluble gp $350-\mathrm{ECD}_{123}$, a $6 \times$ His tag was added at the C-terminus (Figure 1A).

For baculovirus production, Sf9 cells were transfected with recombinant bacmids for each construct. The fusion proteins were secreted into culture medium, and detected by Western blot and dot blot. For soluble gp350-ECD ${ }_{123}$, detection with an anti-His antibody yielded a single band of $\sim 70 \mathrm{kDa}$ under either reducing or non-reducing conditions by Western blot (Figure 1B). This is consistent with gp350-ECD ${ }_{123}$ being a monomer. For gp350$\mathrm{ECD}_{123}-\mathrm{Fc}_{\mathrm{mIgG} 2 \mathrm{a}}$, Fc-detection yielded a $\sim 110 \mathrm{kDa}$ band under reducing condition and $\mathrm{a} \sim 220 \mathrm{kDa}$ band under non-reducing condition. This confirms the dimeric form of gp350-ECD ${ }_{123}-\mathrm{Fc}_{\mathrm{mIgG} 2 \mathrm{a}}$. For gp350-ECD $\mathrm{FL}-\mathrm{Fc}_{\mathrm{mIg} 2 \mathrm{a}}$, the apparent molecular weight under reducing conditions was $\sim 200 \mathrm{kDa}$, and increased to $\sim 450 \mathrm{kDa}$ without reducing reagent. Under non-reducing conditions, smaller products are visible for gp350-ECD ${ }_{\mathrm{FL}}$, which may indicate $\mathrm{Fc}$-containing fragments resulting from partial degradation of the fusion protein. In dot blot, the conformation-dependent neutralizing anti-gp350 monoclonal antibody mAb72A1 specifically recognized all constructs, indicated that the functional region folded correctly (Figure 1C). To purify these fusion proteins, affinity chromatography and gel filtration were performed (Figure 1D). We obtained homogenous preparations for each recombinant protein with molecular weights in agreement with the calculated values (data not shown). Fusion proteins containing gp350-ECD ${ }_{123}$ were well purified while gp350-ECD $\mathrm{FL}_{\mathrm{F}} \mathrm{Fc}$ showed faint unrelated proteins, which were not detected by Western blot (not shown). Overall, the protein analysis shows that the gp350 domains dimerized through Fc domain and were correctly folded and processed through the secretory pathway.

\section{Binding of Fc Fusion Proteins With nAb, mAb72A1}

To assess the proper activity of the recombinant gp350 fusion proteins, we tested their binding to the $\mathrm{CR} 2 / \mathrm{CD} 21$ receptor and their recognition by the $\mathrm{nAb}$ mAb72A1. CR2/CD21 as acts as a receptor for gp350 to mediate entry of EBV into B-lymphocytes $(25,26) . \mathrm{mAb} 72 \mathrm{~A} 1$ is a specific $\mathrm{nAb}$ against gp350, which blocks EBV infection of B-lymphocytes through binding to the gp350 region recognizing $\mathrm{CR} 2 / \mathrm{CD} 21$. We used ELISA and SPR to characterize the affinity and binding kinetics between gp350 and CR2/CD21 or mAb72A1. Purified MBP-hCR2 SCR1-2 was obtained from BL21 bacteria (see Materials and Methods), and mAb72A1 was purified from culture supernatants of HB168 hybridoma cells (24).

By ELISA, the neutralizing mAb $72 \mathrm{~A} 1$ appears to detect all constructs equally well (Figure 2A). However, the refined binding kinetics analysis by SPR shows that the affinity for the dimeric gp350-ED $\mathrm{E}_{123}-\mathrm{Fc}$ increased by about 100 -fold compared with the monomeric gp350-ECD ${ }_{123}$ (Table 1). Both the gp350$\mathrm{ECD}_{\mathrm{FL}}-\mathrm{Fc}$ and gpECD ${ }_{123}-\mathrm{Fc}$ fusion proteins have the same affinity for the antibody (Table 1). Receptor binding was enhanced by fusing gp350-ECD ${ }_{123}$ to Fc. By ELISA, the dimeric constructs bound more soluble receptor than the monomeric gp350-ECD ${ }_{123}$ (Figure 2B), but this may reflect a stoichiometric effect rather than an affinity effect. SPR kinetic analysis shows that the affinity of the receptor for the dimeric gp350-ECD $\mathrm{E}_{123}-\mathrm{Fc}$ increased by about threefold compared with the monomeric gp350-ECD $\mathrm{ED}_{123}$ (Table 1). The affinity of the full ectodomain Fc fusion protein for the receptors is somewhat similar to that of gp350-ECD ${ }_{123}-\mathrm{Fc}$ (Table 1). Overall, the $K_{\mathrm{D}}$ values of Fc fusion proteins were markedly smaller than that of the non-Fc fusion protein. This predicted higher affinity of Fc fusion proteins for the $\mathrm{nAb}$ mAb72A1 and for the receptor hCR2 likely results from the dimerization of $\mathrm{FC}$ fragment.

To confirm the dimeric conformation of gp350 fusion proteins caused by the Fc domain, the molecular weights of gp350 fusion proteins were determined using AUC analysis. As shown in Figure 2C, the molecular weight of gp350-ECD ${ }_{123}-6 \mathrm{His}$ was $70.35 \mathrm{kDa}$, and that of gp350-ECD ${ }_{123}-\mathrm{Fc}_{\mathrm{mIgG} 2 \mathrm{a}}$ was $180.34 \mathrm{kDa}$, respectively. Thus, the Fc constructs have molecular weights corresponding to twice the size of the monomer and correspond to predicted values. 
A

$\begin{array}{ll}\text { - } & \mathrm{BSA} \\ = & \mathrm{gp} 350-\mathrm{ECD}_{123}-6 \mathrm{His} \\ \text { - } & \mathrm{gp} 350-\mathrm{ECD}_{123}-\mathrm{Fc}_{\mathrm{mlg} 2 \mathrm{a}} \\ \text { - } & \mathrm{gp} 350-\mathrm{ECD}_{\mathrm{FL}}-\mathrm{Fc}_{\mathrm{mlg} 2 \mathrm{a}}\end{array}$

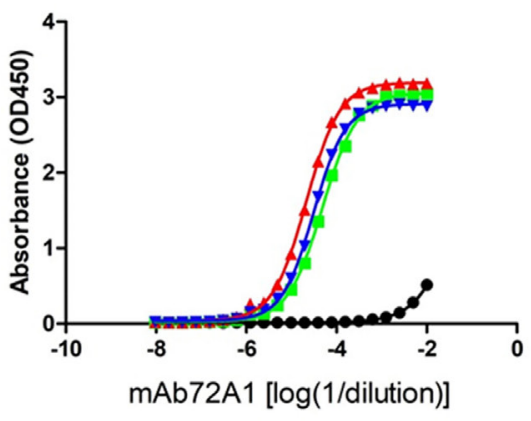

C

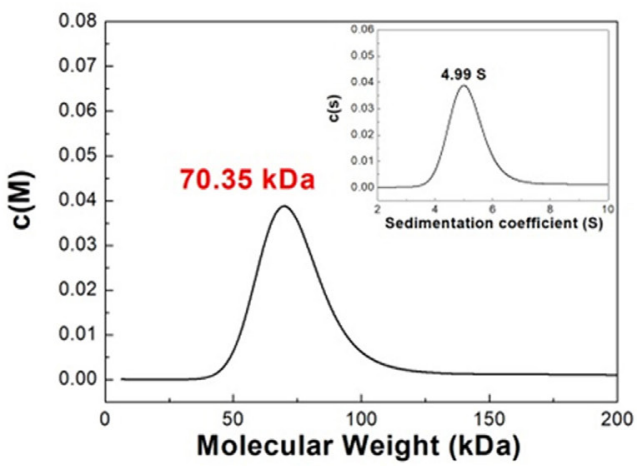

B

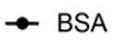

$\rightarrow$ gp350-ECD $123^{-} 6 \mathrm{His}$

$\pm \mathrm{gp} 350-\mathrm{ECD}_{123}-\mathrm{Fc}_{\mathrm{mlgG}} \mathrm{a}$

$\rightarrow \mathrm{gp} 350-\mathrm{ECD}_{\mathrm{FL}}-\mathrm{Fc}_{\mathrm{mlg}} \mathrm{ga}$
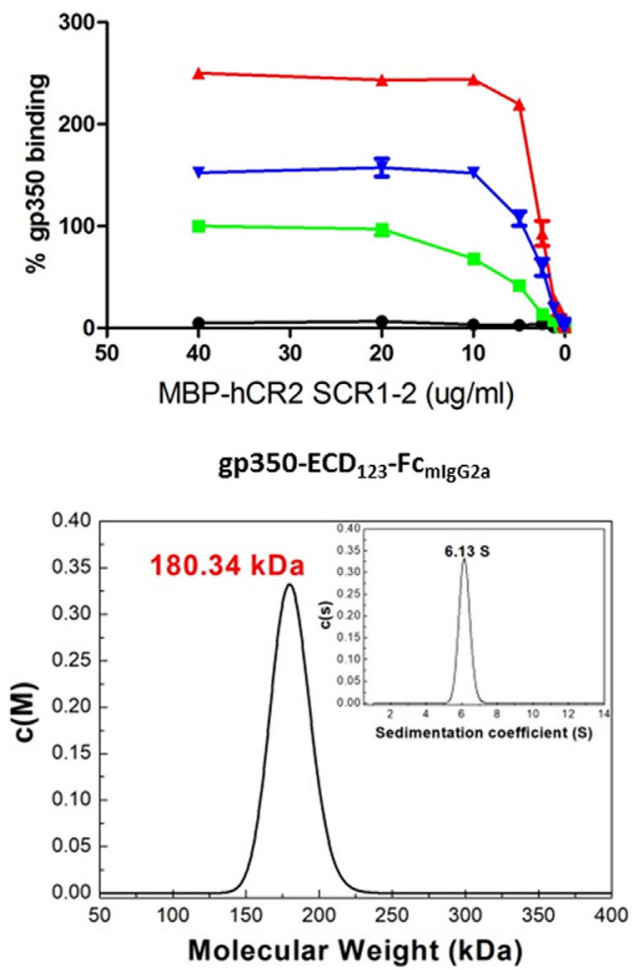

FIGURE 2 | Molecular weight determination and binding kinetics analysis for recombinant gp350. (A) Binding of the indicated forms of recombinant gp350 to conformation-dependent neutralizing monoclonal antibody mAb72A1 by enzyme-linked immunosorbent assay (ELISA). BSA was included as negative control. (B) Binding of the indicated forms of recombinant gp350 to purified receptor MBP-hCR2 SCR1-2 by ELISA. Binding was normalized to maximum binding to monomeric gp350$\mathrm{ECD}_{123}-6$ His. BSA was included as negative control. The Fc fusion proteins bound CR2 more effectively than the monomeric gp350. (C) Analytical ultracentrifugation determination of molecular weight of the indicated forms of recombinant gp350 after purification. Sedimentation coefficients and molecular weights are indicated.

TABLE 1 | Affinity and binding kinetics of recombinant gp350 with mAb72A1 neutralizing antibody and hCR2 SCR1-2 receptor determined by surface plasmon resonance.

\begin{tabular}{|c|c|c|c|c|}
\hline & $K_{\mathrm{D}}(\mathrm{M})$ & $k_{\mathrm{a}}(1 / \mathrm{M} \mathrm{s})$ & $k_{\mathrm{d}}(1 / \mathrm{s})$ & $\chi^{2}$ \\
\hline \multicolumn{5}{|l|}{ mAb72A1 } \\
\hline gp350-ECD ${ }_{123}-6 \mathrm{His}$ & $1.525 \times 10^{-8}$ & $5.254 \times 10^{4}$ & $8.014 \times 10^{-4}$ & 0.465 \\
\hline gp350-ECD ${ }_{123}-\mathrm{Fc}_{\mathrm{mlg} 2 \mathrm{a}}$ & $1.324 \times 10^{-10}$ & $6.904 \times 10^{5}$ & $9.141 \times 10^{-5}$ & 2.040 \\
\hline gp350-ECD $\mathrm{FL}-\mathrm{FC}_{\mathrm{mlgG} 2 \mathrm{a}}$ & $1.819 \times 10^{-10}$ & $5.817 \times 10^{5}$ & $1.058 \times 10^{-4}$ & 2.490 \\
\hline \multicolumn{5}{|l|}{ hCR2 SCR1-2 } \\
\hline gp350-ECD ${ }_{123}-6 \mathrm{His}$ & $2.942 \times 10^{-7}$ & $4.783 \times 10^{3}$ & $1.407 \times 10^{-3}$ & 0.560 \\
\hline gp350-ECD ${ }_{123}-\mathrm{Fc}_{\mathrm{mlg} 2 \mathrm{a}}$ & $9.463 \times 10^{-8}$ & $4.053 \times 10^{4}$ & $3.835 \times 10^{-3}$ & 0.610 \\
\hline gp350-ECD ${ }_{\mathrm{FL}}-\mathrm{FC}_{\mathrm{mlgG} 2 \mathrm{a}}$ & $6.847 \times 10^{-8}$ & $1.755 \times 10^{4}$ & $1.201 \times 10^{-3}$ & 0.839 \\
\hline
\end{tabular}

\section{Fc Fusion Antigen Were Notably More Immunogenic Than Monomeric gp350- $E D_{123}-6$ His in the Presence of Alum or CpG Adjuvants}

To determine the immunogenicity of $\mathrm{Fc}$ fusion proteins in vivo, $\mathrm{BALB} / \mathrm{c}$ mice were immunized with gp350-Fc fusion proteins or monomeric gp350. Mice were injected and boosted i.p. with each antigen in the presence of Imject Alum adjuvant according to the schedule in Figure 3A. The specific anti-gp350 antibody titers were tested by ELISA against the monomeric gp350-ECD ${ }_{123}$. Serum titers from mice immunized with either gp350-Fc fusion protein were very significantly $(p<0.001)$ higher than that of the control group immunized with monomeric gp350 for both 1 and $20 \mu \mathrm{g}$ doses (Figure 3B). The difference between monomeric and Fc-based gp350 antigen increased after a single boost for both doses tested. Considering that Fc fusion antigens could elicit an antibody response after mucosal immunization, we also immunized and boosted mice intranasally (i.n.) in the presence of CpG1826. Mice were boosted 2 weeks after the primary injection, and specific antibody titer against gp350 was determined 3 weeks later using ELISA (Figure 3A). As shown in Figure 3C, the serum titers of mice immunized i.n. with gp350-Fc fusion antigens were drastically higher than titers of mice immunized with monomeric gp350, which were similar to background signal likely due to non-specific serum IgG. After i.p. or i.n. injection, antibody titers in sera of mice immunized with gp350-ECD $\mathrm{FL}-\mathrm{Fc}_{\mathrm{mIgG2a}}$ appeared 
A

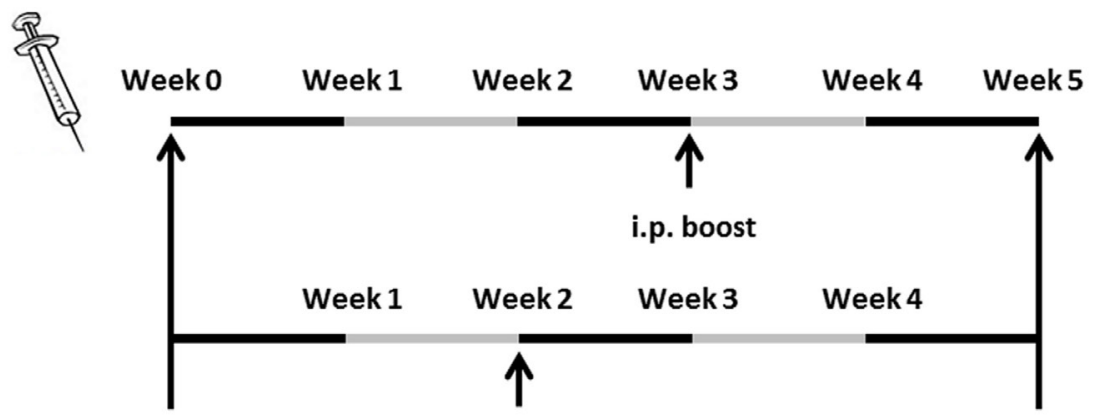

Pre-immunization serum

i.n. boost

Serum test collection and primary immunization

B

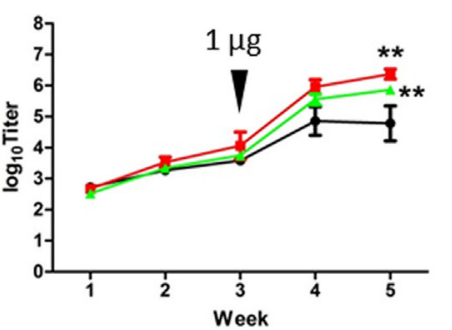

$\rightarrow$ gp $350-\mathrm{ECD}_{123}-6 \mathrm{His}$

- gp $350-\mathrm{ECD}_{123}-\mathrm{Fc}_{\mathrm{mlg}} \mathrm{ag}$

$\rightarrow \mathrm{gp} 350-\mathrm{ECD}_{\mathrm{FL}}-\mathrm{Fc}_{\mathrm{mlg}} \mathrm{gaa}$

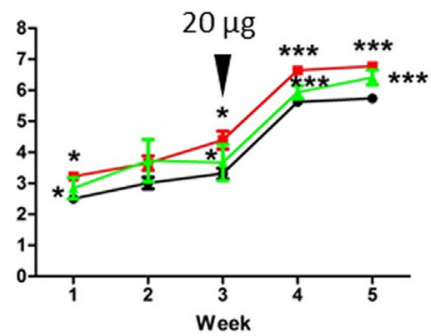

C
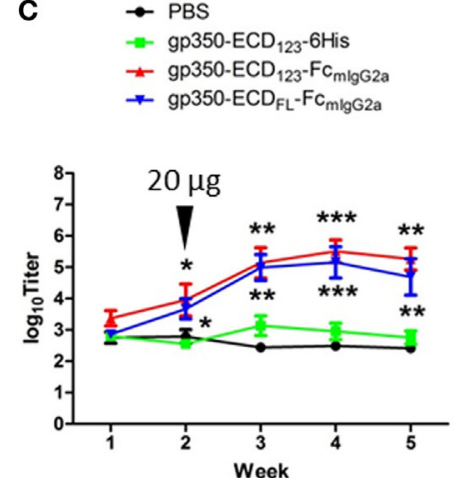

FIGURE 3 | gp350 proteins fused with $\mathrm{FC}_{\mathrm{m} \text { lgG2a }}$ domain were notably more immunogenic than monomers in the presence of adjuvants. (A) Diagram of the immunization protocols. Mice were boosted on week 2 for i.n. group or week 3 for i.p. group. (B) Mice (five per group) were immunized i.p. with $1 \mu \mathrm{gg}$ (left panel) or $20 \mathrm{\mu g}$ (right panel) recombinant proteins in Imject Alum adjuvant. (C) Mice (five per group) were immunized i.n. with PBS or recombinant gp350 proteins mixed with CpG1826. Black arrowheads indicate the times of boosts. Each data point represents mean $\pm \operatorname{SEM}(n=5)$. Significance $\left({ }^{*} p \leq 0.05,{ }^{* *} p<0.01\right.$, and $\left.{ }^{* \star *} p<0.001\right)$ between Fc fusion proteins versus monomer gp350 proteins is shown.

slightly, but not significantly, lower than titers in sera of mice immunized with gp350-ECD $123-\mathrm{Fc}_{\mathrm{mIgG} 2 \mathrm{a}}$. Overall, regardless of the immunization route, Fc-based gp350 antigens were more immunogenic than the native monomeric gp350.

\section{Immunization With Fc Fusion Antigens Potently Induced Production of nAbs}

To address the presence of nAbs in sera of gp350 immunized mice, competition ELISA and SPR were carried out against the neutralizing mAb72A1. This competition approach demonstrates the presence of antibodies in serum, which share overlapping epitopes with known strong neutralizing monoclonal antibodies. This approach was validated for herpes simplex virus entry glycoproteins, where the ability of serum Ig to compete with specific nAbs directly correlated with the neutralizing ability of serum samples from infected and vaccinated individuals $(48,49)$. Wilson and Morgan showed a direct correlation between mAb72A1 competition and ability of mouse sera to neutralize infection (50). In the present competition ELISA, sera from mice immunized with gp350-Fc inhibited the binding of the neutralizing monoclonal antibody mAb72A1 to gp350 significantly better than sera from mice immunized with monomeric gp350
(Figures 4A,B). At low serum dilution, more than $80 \%$ of the binding of the $\mathrm{nAb}$ could be blocked by sera from mice, which received the gp350-Fc antigens. It did not escape us that sera from mice mock-immunized with PBS have high competition effect in this setting (Figure 4B). We decided to show the complete data rather than subtracting this background. Similar effect was seen previously in competition experiments (47). This indicates that i.n. immunization with monomeric gp350-ECD ${ }_{123}$ leads to low or no production of nAbs similar to mAb721A1.

The competition percentage was also evaluated by SPR for i.p. and i.n. immunizations (Figure 4C). Here, the competitive percentage represents the $\%$ reduction of serum Ig binding to gp350 following binding of the potent neutralizing mAb72A1. mAb72A1 reduced the gp350 binding ability of seric Ig from mice immunized i.p. with gp350-ECD ${ }_{123}-\mathrm{Fc}$ and gp350-ECD $\mathrm{FL}_{\mathrm{FL}}-\mathrm{FC}$ by 12 and $8 \%$, respectively. When i.n. immunization was performed, the competitive percentages were 8 and $6 \%$ for the respective dimeric antigens. By contrast, binding of serum Ig from mice immunized with the monomeric gp350-ECD ${ }_{123}-6 \mathrm{His}$ was not affected by the neutralizing monoclonal antibody. These competition data show that the sera from mice immunized with gp350-Fc antigens, but not with monomeric gp350, contained antibodies that detect the neutralizing epitope specified by mAb72A1. 


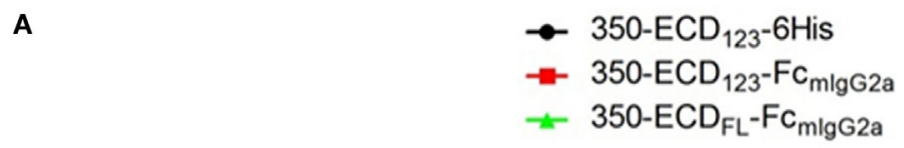

$1 \mu \mathrm{g}$

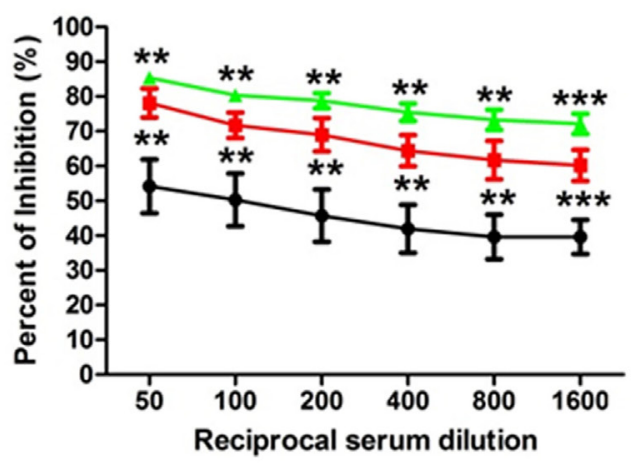

B
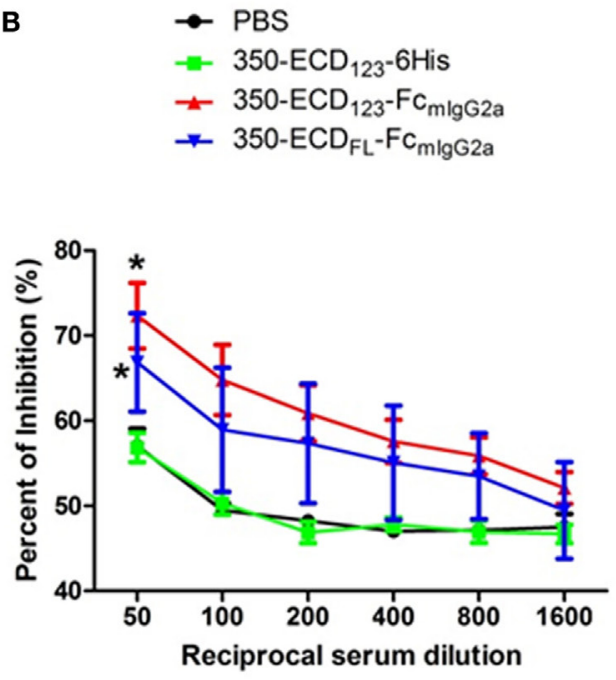

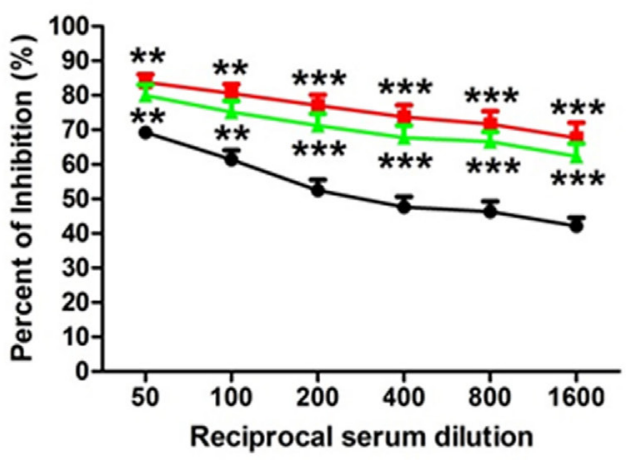

$20 \mu \mathrm{g}$

C

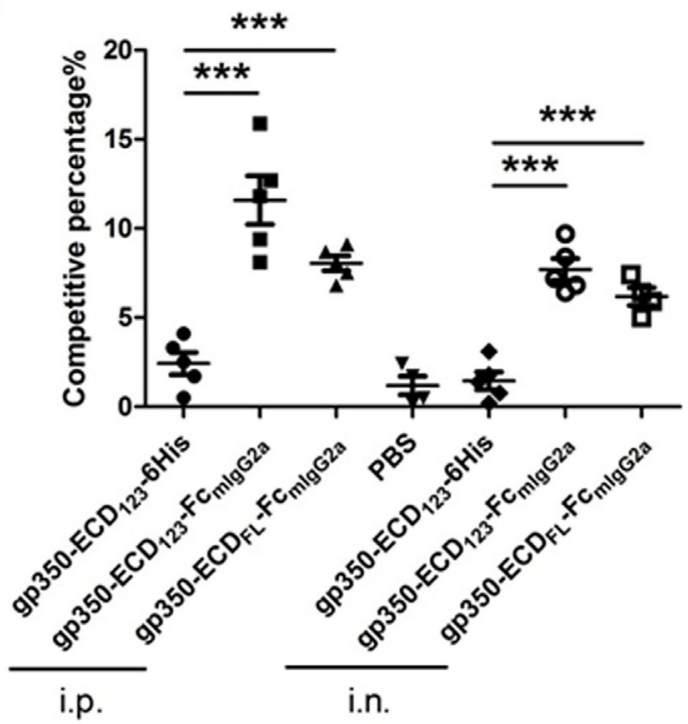

FIGURE 4 | Immunization with Fc-based recombinant gp350 proteins elicits dramatically higher neutralizing titers than monomers. (A) Competition enzyme-linked immunosorbent assay (ELISA). BALB/c mice (five per group) were immunized i.p. with $1 \mu \mathrm{g}$ (left panel) or $20 \mu \mathrm{g}$ (right panel) of the indicated proteins in Alum adjuvant. Serum dilutions were used to block binding of neutralizing monoclonal antibody mAb72A1 to monomeric gp350 in competition ELISA. Percentage of inhibition of mAb72A1 binding is reported. (B) Competition ELISA. BALB/c mice (five per group) were immunized i.n. with $20 \mu g$ proteins assisted by CpG. Sera were analyzed for the ability to block mAb72A1 as in panel (A). Each data point represents mean \pm SEM $(n=5)$. (C) Competition by surface plasmon resonance (SPR). Neutralizing mAb72A1 was used to compete binding of serum immunoglobulin from mouse immunized with the indicated antigens to immobilized monomeric gp350 by SPR. The percentage of reduction of serum Ig binding is indicated. Each symbol represents the serum of one mouse (five mice per group), and the bars show mean \pm SEM values. Significance $\left({ }^{\star} p \leq 0.05,{ }^{\star \star} p<0.01\right.$, and $\left.{ }^{\star \star *} p<0.001\right)$ between Fc fusion proteins versus monomer gp350 proteins is shown.

To determine whether the nAbs detected by competitive ELISA and SPR in Fc-350 sera have anti-EBV activity, the ability of these sera to block EBV infection of B-lymphocytes was tested. In this neutralization assay, $\mathrm{EBV}_{\mathrm{GFP}}$ produced from CNE2 cells was incubated with diluted sera, and used to infect Akata cells (EBV negative). The neutralizing monoclonal mAb72A1 was included as a positive control.

Figure 5A shows the results for sera from mice immunized i.p. with $20 \mu \mathrm{g}$ of the indicated antigens when diluted $10 \times$ or 40×. As expected, preimmune serum added only a limited effect compared with the negative control. Globally, immunization with the monomeric gp350-ECD ${ }_{123}-6 \mathrm{His}$ did not elicit significant protection, although a couple of sera had more noticeable neutralizing effect compared with preimmune serum. By contrast, sera from mice immunized with either gp350-Fc construct, blocked infection efficiently at both dilutions (10X and $40 \times)$. The Fc-based constructs were significantly more potent than monomeric gp350 at both dilutions. The results of EBV neutralization assay with sera of mice that received a lower dose of antigen $(1 \mu \mathrm{g})$ follow a similar trend (Figure 5B). 


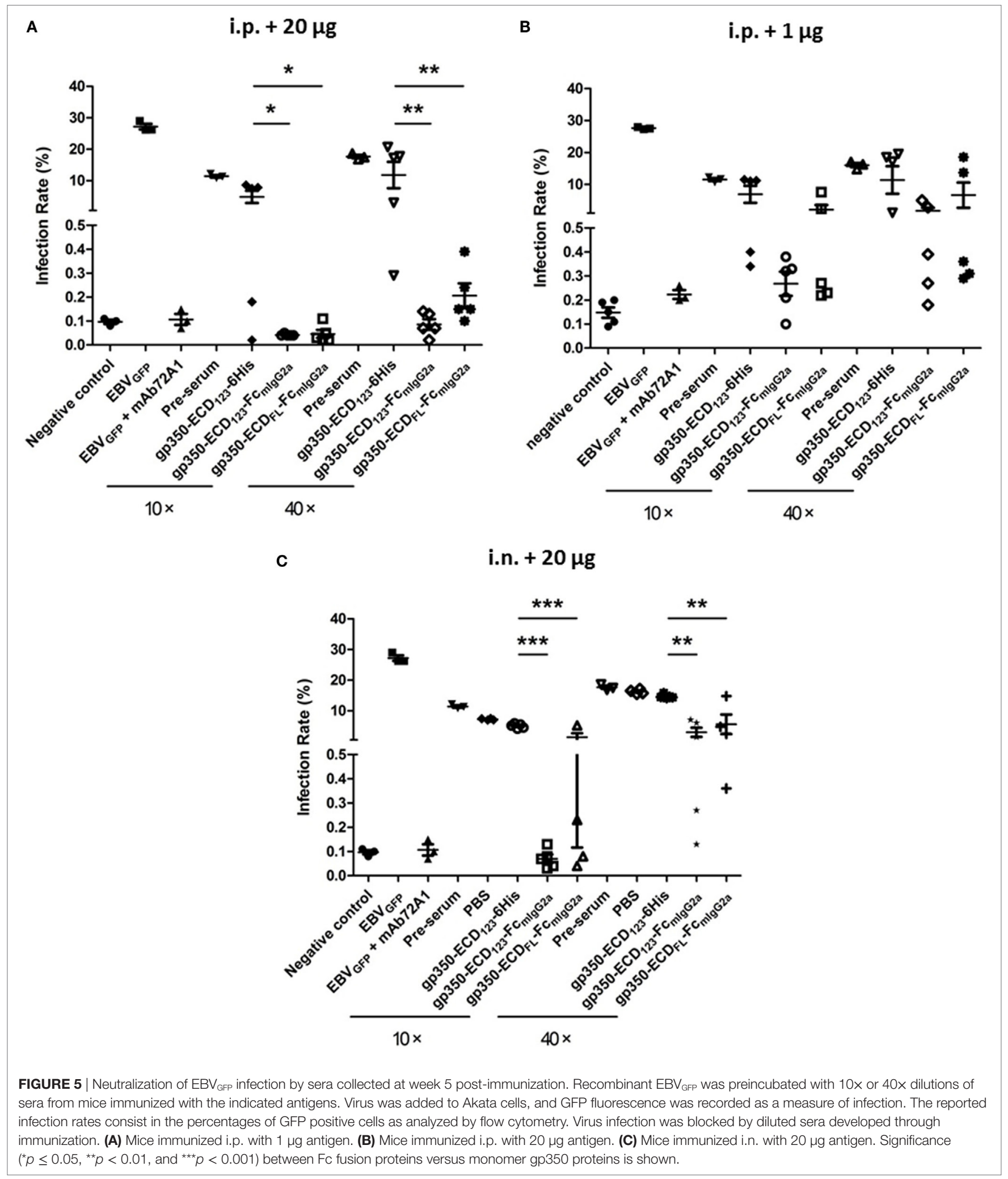

However, the absolute neutralization potential was diminished, especially for the gp350-ECD $\mathrm{FL}_{\mathrm{FL}}-\mathrm{Fc}$, which was not significantly better than monomeric gp350. Sera from mice immunized with
gp350-ECD ${ }_{123}-\mathrm{Fc}$ were only significantly protective when diluted 10 -fold. At $40 \times$ dilution, it was limited to some but not all mice in each immunized group. 
After intranasal immunization with $20 \mu \mathrm{g}$ of antigen, gp350$\mathrm{ECD}_{123}-\mathrm{Fc}$, provided $100 \%$ neutralization with $10 \times$ diluted serum (Figure 5C). It was more efficient than gp350-ECD $\mathrm{FL}_{\mathrm{L}} \mathrm{Fc}$, but both Fc constructs were significantly better than monomeric gp350$\mathrm{ECD}_{123}-6 \mathrm{His}$ at both dilutions of sera.

We also tested whether there was a direct correlation between total anti-gp350 titers and ability of sera from different groups to block EBV infection of B cells. We found a strong linear correlation between total anti-gp350 titers (5 weeks post-immunization) and neutralizing activity (Figure S1 and Table S1 in Supplementary Material). The same correlation was observed at different dilution of sera $(10 \times, 40 \times)$ used in these assays. The linear correlation occurred across all three forms of antigens for each route of immunization. Thus, Fc-based dimerization increased total titers and neutralizing titers in a similar manner. Overall, these data indicate that the immunogenicity of gp $350-\mathrm{ECD}_{123}$ was notably enhanced by fusion with an Fc domain.

\section{Immunization With gp350-ECD ${ }_{123}-\mathrm{Fc}_{\mathrm{mlgG}}$ Elicited Markedly Higher Titers of IgG Isotypes and IgA}

We compared the titers of different IgG isotypes between mice immunized with the various gp350 antigens (Figure 6). This analysis confirms that gp350-Fc is more immunogenic than monomeric gp350. The Fc-based antigens elicited more IgG1 and $\operatorname{IgG} 2 \mathrm{~b}$ than the monomeric counterpart gp $350-\mathrm{ECD}_{123}-6 \mathrm{His}$ after i.p. immunization (Figures 6A,C). And after i.n. immunization, the gp350-Fc antigens induced markedly more IgG1, IgG2a, and IgG2b. Interestingly, all gp350 antigens elicited the same titer of IgG3, mostly after i.p. immunization (Figure 6D). The IgA serum titer was tested for mice immunized intranasally (Figure 6E). The specific IgA titers elicited by the immunization with Fc fusion proteins increased to some extent and follow the same trend as the IgG subtypes, although there is no statistical variation in this case. Enhancing the mucosal immunogenicity of gp350-Fc antigens may

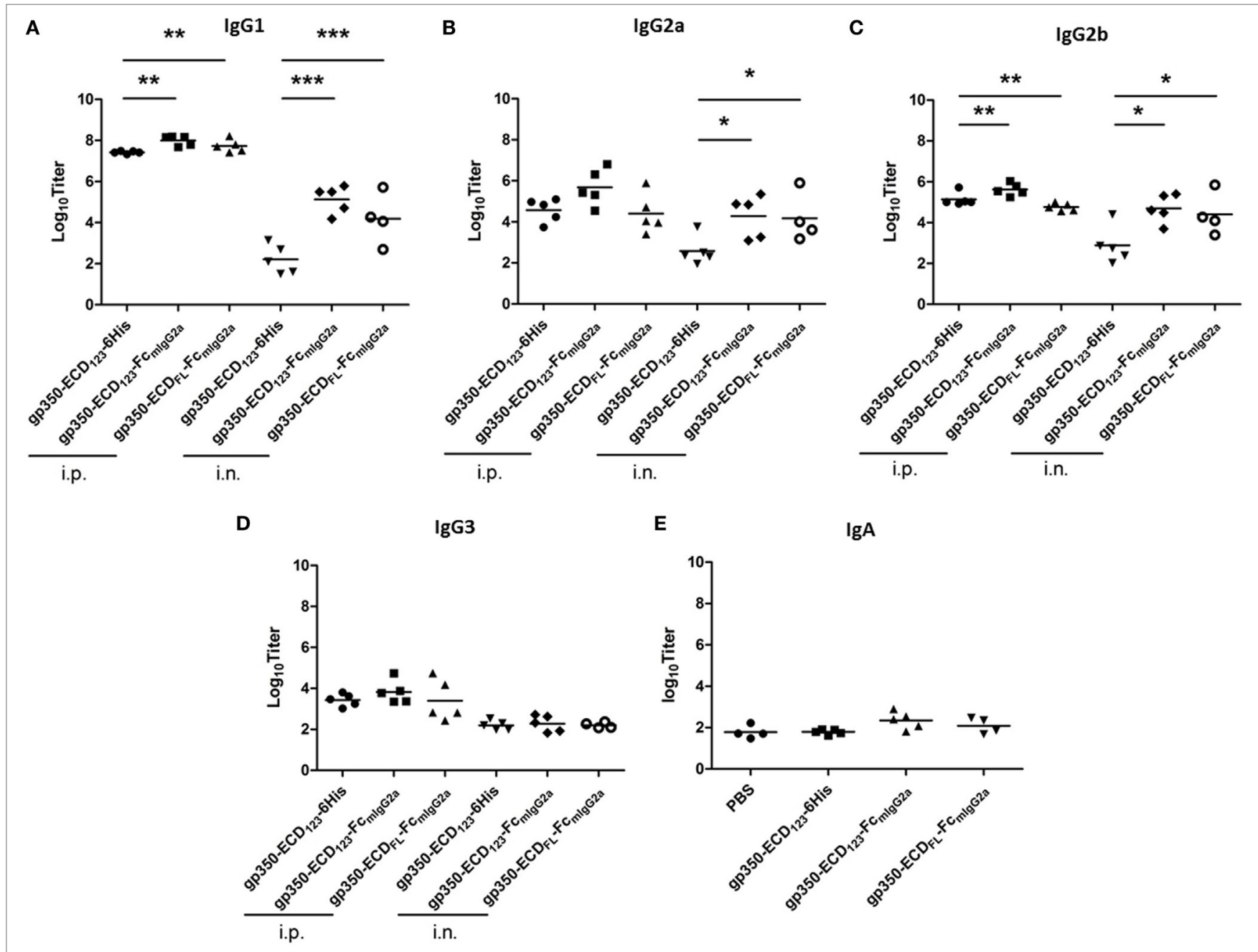

FIGURE 6 | Specific titers of anti-gp350 lgG isotypes and IgA in sera are markedly elevated post-immunization with Fc-based gp350 proteins. (A-D) Titers of gp350-specific IgG subtypes were determined in sera (5 weeks post-immunization) of mice immunized i.p. or i.n. with $20 \mu \mathrm{g}$ of the indicated antigen. (E) Anti-gp350 IgA serum titers from mice immunized i.n. with $20 \mu \mathrm{g}$ of the indicated antigens. Each symbol represents an individual serum. Horizontal bars represent mean values. Significance $\left({ }^{\star} p \leq 0.05,{ }^{\star *} p<0.01\right.$, and $\left.{ }^{* \star *} p<0.001\right)$ between Fc fusion proteins versus monomer gp350 proteins is shown. 
be improved by using adjuvants that are better adapted than CpG to elicit mucosal immunity [e.g., Poly(I:C), PEI]. Overall, these data confirm the highest immunogenicity of the Fc-based construct gp350-ECD ${ }_{123}-\mathrm{Fc}$.

\section{DISCUSSION}

In our systematic study of the immunogenicity of the EBV envelope gp350 antigen, the full-length ectodomain (gp350-ECD ${ }_{\mathrm{FL}}$ ) or functional domains 1-2-3 of the glycoprotein (gp350-ECD ${ }_{123}$ ) were fused to the Fc domain of mouse IgG2a. We showed that the Fc portion led to the dimerization of the normally monomeric gp350. Fusion with the Fc domain did not affect the native conformations of the receptor-binding domain and putative neutralizing epitopes. Indeed, the recombinant antigens with or without Fc domains have similar binding affinity and kinetics for the potent $\mathrm{nAb}, \mathrm{mAb} 72 \mathrm{~A} 1$, and for the receptor, hCR2/CD21. More importantly, immunization with Fc-based gp 350 fusion antigens elicited markedly more potent protection against EBV infection of B cells compared with monomeric gp 350 . This enhanced protection correlates with higher titers of nAbs in sera of mice immunized with the Fc-based gp 350 constructs. When comparing both $\mathrm{Fc}$-based constructs, it is not clear why gp $350-\mathrm{ECD}_{123}-\mathrm{Fc}$ was a more potent immunogen compared with the full ectodomain gp 350-ECD $D_{\mathrm{FL}}-\mathrm{Fc}$. It may be because it contains fewer nonneutralizing epitopes compared with the full-length ectodomain. Alternatively, it may be caused by eliciting different Ig isotypes, although the contribution of each isotype to neutralization has not been determined. Finally, gp $350-\mathrm{ECD}_{123}-\mathrm{Fc}$ may be a more stable antigen with less degradation than gp $350-\mathrm{ECD}_{\mathrm{FL}}-\mathrm{Fc}$. In all our assays, we also observed a direct correlation between total anti-gp350 titers and inhibition of infection of B-cells (Figure S1 and Table S1 in Supplementary Material). This finding across three different forms of the gp350 antigens supports previous observations that anti-gp350 titers correlate better with inhibition of B-cell infection than anti-gp42 titers in humans (51).

The immunogenicity of monomer antigens is frequently enhanced through multimerization (52-55). In recent years, research on the development of EBV prophylactic vaccines has focused on the use of multimerization elements to improve immunogenicity. Cui et al. reported that a tetrameric gp350 linked by a leucine zipper domain and a trimer of $\mathrm{gH} / \mathrm{gL}$ linked by the $\mathrm{T} 4$ fibritin foldon elicited more potent antigen-specific IgG and cytokine responses $(56,57)$. Kanekiyo et al. tested the immunogenicity of ferritin-based gp 350 vaccine candidates in mice and non-human primates (32). Their results suggested that this approach induced potent nAbs. In the absence of direct comparison, one can only speculate about the most effective way of presenting gp350 as a dimer or a multimer. The Fc fusion approach has the advantage of having been validated in other human clinical trials $(37,43)$. Also, gH/gL-EBNA1 and gB-LMP2 fusion proteins have been showed to induce high antibody titers and EBV-specific T-cell responses in mice (58). Moreover, when fused with KLH, peptides, which have high affinity to EBV host cells, led to the production of neutralizing monoclonal antibodies against $\operatorname{EBV}(59,60)$. Multimerization elements have shown many application prospects in these studies. However, the clinical safety and durability of these different approaches need further investigation, if possible in direct comparison, to be considered for clinical use.

The safety of Fc fusion protein as drugs has been widely validated in numerous clinical trials $(37,43)$. The Fc domain endows the recombinant antigens with a slower renal clearance rate due to dimerization and increased molecular weight. Through interaction with its corresponding receptor, FcRn, the plasma half-life of Fc fusion antigens was remarkably increased $(37,40,42)$. Furthermore, the dimerization through $\mathrm{Fc}$ may induce a more efficient $\mathrm{B}$ cell receptor cross-linking (57). Based on the advantages brought by fusion with the Ig Fc domain, the immunity of antigens was potently enhanced (61). Besides, the antigens attached to Fc domain could be presented to APCs to elicit mucosal immunity. Altogether, the Fc-based version of an antigen is considered superior to its wild-type monomeric counterpart in preventing diseases acquired through mucosae $(47,62)$. EBV, which was described as one "kiss" virus, initiates infection of the host by infecting mucous epithelial cells (63). Consequently, this Fc-based approach serves as a new template to develop EBV prophylactic vaccine that target the initial infection of mucosa. Our data support the benefit of fusion of gp350 with the $\operatorname{IgG~Fc}$ domain which has been preferred in vaccine design (i.e., mouse IgG2a or human IgG1). However, Fc domains from other Ig subtypes such as IgE and IgM, which have various affinities for different receptors, could be envisaged in further studies (37). For tests in non-human primates and for clinical use, human IgG1 Fc is preferred. The ability of hIGg1 to enhance immunogenicity of EBV gp350 is expected to be similar to that of the constructs based on mIgG2a presented here. Characterization of human Fc-based gp350 antigens is ongoing.

Previous gp350-based multimeric antigens have been tested in mouse models, including tetrameric gp350, virus-like particles, and ferritin nanoparticles $(32,57,64)$. Due to different readout assays and protocols of injections, and because doses cannot be directly compared, any quantitative comparisons of total and neutralizing titers have to be interpreted very carefully. All these studies compare multimeric gp350 to a monomeric antigen, as we did here. This provides a framework to normalize and compare the efficacy of each approach. We found that Fc-based dimerization increased titers by 10 - to 100 -fold over monomeric gp 350 (Figures 3B,C). This is in the range of titer increase reported for other multimeric forms of gp350 (32, 57, 64). Addition of Fc domains increased neutralization efficacy by about 100 -fold (Figure 5). By comparison, the Fc-based approaches (20 $\mu \mathrm{g}$ i.n. or i.p.) appear as efficient ways of increasing anti-gp350 neutralization titers. Clearly, a side-by-side comparison with matched doses and analyses is needed to directly identify the most promising vaccine candidates in terms of efficacy and safety.

In previous clinical attempts, prophylactic vaccines targeting gp350 failed to block EBV infection in humans despite their ability to induce neutralizing Abs in rodent or non-human primates (17). In our study, when BALB/c mice were immunized with similar soluble gp350 monomers, only a few sera could block EBV infection of B-lymphocytes in vitro. By comparison, immunization with Fc-based recombinant gp350 increased neutralization titers and protection ability in vitro. This suggests that Fc-based gp350 antigens could provide a more potent protection 
against EBV infection, which may be due to the interaction of the Fc domain with its corresponding receptors. Furthermore, considering the complexity of the EBV virion envelope, a combination of gp350-Fc with other glycoproteins antigens could be included in candidate vaccine formulations. This may provide broader protection against EBV, which uses different subsets of glycoproteins to infect lymphocytes and epithelial cells. For instance, the potential application of $\mathrm{gH} / \mathrm{gL}$ heterodimer and $\mathrm{gB}$ (a natural trimer) in EBV vaccine preparation has been discussed in previous reports since these essential glycoproteins are targeted by nAbs (56). However, very little information is available about the rational molecular design and optimal adjuvant formulation. Though some efforts have been made to investigate the usage of EBV $\mathrm{gH} / \mathrm{gL}$ dimer and $\mathrm{gB}$ in vaccine research, it remains to be determined whether such antibodies would cut off the EBV infection in non-human primates.

In conclusion, our data with EBV gp350 suggest that the rational design to fuse the IgG Fc domain with the ectodomains of EBV glycoproteins could enhance immunogenicity, thereby providing more marked and universal protection against EBV infection. This strategy will guide further investigation to design EBV prophylactic vaccine, such as combinations of several EBV surface glycoproteins.

\section{DATA AVAILABILITY STATEMENT}

The authenticity of this article has been validated by uploading the key raw data onto the Research Data Deposit public platform (www.researchdata.org.cn), with the approval number RDDB2018000295.

\section{ETHICS STATEMENT}

All experiments involving mice were approved by the Institutional Animal Care and Use Committee at the Sun Yat-Sen University Cancer Center, and the animals were cared for in accordance with the institutional guidelines. The mice were purchased from Beijing Vital River Laboratory Animal Technology Co., Ltd. (the joint venture of Charles River Laboratories in China).

\section{REFERENCES}

1. Young LS, Yap LF, Murray PG. Epstein-Barr virus: more than 50 years old and still providing surprises. Nat Rev Cancer (2016) 16(12):789-802. doi:10.1038/ nrc.2016.92

2. Epstein MA, Achong BG, Barr YM. Virus particles in cultured lymphoblasts from Burkitt's lymphoma. Lancet (1964) 1(7335):702-3. doi:10.1016/S01406736(64)91524-7

3. Young LS, Rickinson AB. Epstein-Barr virus: 40 years on. Nat Rev Cancer (2004) 4(10):757-68. doi:10.1038/nrc1452

4. de Martel C, Ferlay J, Franceschi S, Vignat J, Bray F, Forman D, et al. Global burden of cancers attributable to infections in 2008: a review and synthetic analysis. Lancet Oncol (2012) 13(6):607-15. doi:10.1016/S1470-2045(12) 70137-7

5. Khan G, Hashim MJ. Global burden of deaths from Epstein-Barr virus attributable malignancies 1990-2010. Infect Agent Cancer (2014) 9(1):38. doi:10.1186/1750-9378-9-38

\section{AUTHOR CONTRIBUTIONS}

YZ conceived the project and revised the manuscript; BZ designed and performed most of the experiments; XZ carried out collection of mouse serum samples and provided assistance for article supervision; CK contributed to data analysis and manuscript writing; SS carried out the AUC analysis experiment; HZ and LG cultured the insect cells; MX, LF, QF, and MZ provided assistance for some experiments; YX provided assistance on nuclei acid extraction. All the authors approved the final manuscript.

\section{ACKNOWLEDGMENTS}

We are grateful to Prof. Hui Zhang (Zhongshan School of Medicine, SYSU), Prof. Ningshao Xia (Xiamen University), Prof. Qinjian Zhao (Xiamen University), Prof. Yixin Chen (Xiamen University), Prof. Rong Xiang (Nankai University), and Prof. Lindsey M. Hutt-Fletcher (Louisiana State University) for their suggestion and assistance. We thank Prof. Richard Longnecker (Northwestern University) for kindly providing antibodies against EBV glycoproteins.

\section{FUNDING}

This work was supported by grants from the National Key R\&D Program of China (No. 2016YF0902000), the Key Program of the National Natural Science Foundation of China (No. 81430059), the China Postdoctoral Science Foundation (No. 2017M612797), the Health \& Medical Collaborative Innovation Project of Guangzhou City, China (No. 201400000001), and the Foundation of the Ministry of Science and Technology of Guangdong Province (No. 2015B050501005). National Science Foundation of China (No. 81702001).

\section{SUPPLEMENTARY MATERIAL}

The Supplementary Material for this article can be found online at https://www.frontiersin.org/articles/10.3389/fimmu.2018.00932/ full\#supplementary-material.

6. Cohen JI. Epstein-Barr virus infection. N Engl J Med (2000) 343(7):481-92. doi:10.1056/NEJM200008173430707

7. Cohen JI. Optimal treatment for chronic active Epstein-Barr virus disease. Pediatr Transplant (2009) 13(4):393-6. doi:10.1111/j.1399-3046.2008.01095.x

8. Harabuchi Y, Yamanaka N, Kataura A, Imai S, Kinoshita T, Mizuno F, et al. Epstein-Barr virus in nasal T-cell lymphomas in patients with lethal midline granuloma. Lancet (1990) 335(8682):128-30. doi:10.1016/0140-6736(90) 90002-M

9. Jones JF, Shurin S, Abramowsky C, Tubbs RR, Sciotto CG, Wahl R, et al. T-cell lymphomas containing Epstein-Barr viral DNA in patients with chronic Epstein-Barr virus infections. N Engl J Med (1988) 318(12):733-41. doi:10.1056/NEJM198803243181203

10. Nagington J, Gray J. Cyclosporin A immunosuppression, Epstein-Barr antibody, and lymphoma. Lancet (1980) 1(8167):536-7. doi:10.1016/ S0140-6736(80)92784-1

11. Pope JH. Establishment of cell lines from peripheral leucocytes in infectious mononucleosis. Nature (1967) 216(5117):810-1. doi:10.1038/216810a0 
12. Poppema S, van Imhoff G, Torensma R, Smit J. Lymphadenopathy morphologically consistent with Hodgkin's disease associated with Epstein-Barr virus infection. Am J Clin Pathol (1985) 84(3):385-90. doi:10.1093/ajcp/ 84.3.385

13. Tsao SW, Tsang CM, To KF, Lo KW. The role of Epstein-Barr virus in epithelial malignancies. J Pathol (2015) 235(2):323-33. doi:10.1002/path.4448

14. Wu TC, Mann RB, Charache P, Hayward SD, Staal S, Lambe BC, et al. Detection of EBV gene expression in Reed-Sternberg cells of Hodgkin's disease. Int J Cancer (1990) 46(5):801-4. doi:10.1002/ijc.2910460509

15. Lasaviciute G, Bjorkander S, Carvalho-Queiroz C, Hed Myrberg I, Nussbaum B, Nilsson C, et al. Epstein-Barr virus, but not cytomegalovirus, latency accelerates the decay of childhood measles and rubella vaccine responses a 10-year follow-up of a Swedish birth cohort. Front Immunol (2017) 8:1865. doi:10.3389/fimmu.2017.01865

16. Balfour HH Jr. Progress, prospects, and problems in Epstein-Barr virus vaccine development. Curr Opin Virol (2014) 6:1-5. doi:10.1016/j.coviro.2014.02.005

17. Cohen JI. Epstein-Barr virus vaccines. Clin Transl Immunology (2015) 4(1):e32. doi:10.1038/cti.2014.27

18. Cohen JI, Fauci AS, Varmus H, Nabel GJ. Epstein-Barr virus: an important vaccine target for cancer prevention. Sci Transl Med (2011) 3(107):107fs107. doi:10.1126/scitranslmed.3002878

19. Hutt-Fletcher LM. Epstein-Barr virus entry. J Virol (2007) 81(15):7825-32. doi:10.1128/JVI.00445-07

20. Mohl BS, Chen J, Sathiyamoorthy K, Jardetzky TS, Longnecker R. Structural and mechanistic insights into the tropism of Epstein-Barr Virus. Mol Cells (2016) 39(4):286-91. doi:10.14348/molcells.2016.0066

21. Nemerow GR, Mold C, Schwend VK, Tollefson V, Cooper NR. Identification of gp350 as the viral glycoprotein mediating attachment of Epstein-Barr virus (EBV) to the EBV/C3d receptor of $\mathrm{B}$ cells: sequence homology of gp350 and C3 complement fragment C3d. J Virol (1987) 61(5): $1416-20$.

22. Szakonyi G, Klein MG, Hannan JP, Young KA, Ma RZ, Asokan R, et al. Structure of the Epstein-Barr virus major envelope glycoprotein. Nat Struct Mol Biol (2006) 13(11):996-1001. doi:10.1038/nsmb1161

23. Johannsen E, Luftig M, Chase MR, Weicksel S, Cahir-McFarland E, Illanes D, et al. Proteins of purified Epstein-Barr virus. Proc Natl Acad Sci U S A (2004) 101(46):16286-91. doi:10.1073/pnas.0407320101

24. Hoffman GJ, Lazarowitz SG, Hayward SD. Monoclonal antibody against a 250,000-dalton glycoprotein of Epstein-Barr virus identifies a membrane antigen and a neutralizing antigen. Proc Natl Acad Sci U S A (1980) 77(5): 2979-83. doi:10.1073/pnas.77.5.2979

25. Lowell CA, Klickstein LB, Carter RH, Mitchell JA, Fearon DT, Ahearn JM. Mapping of the Epstein-Barr virus and C3dg binding sites to a common domain on complement receptor type 2. J Exp Med (1989) 170(6):1931-46. doi:10.1084/jem.170.6.1931

26. Nemerow GR, Mullen JJ III, Dickson PW, Cooper NR. Soluble recombinant CR2 (CD21) inhibits Epstein-Barr virus infection. J Virol (1990) 64(3):1348-52.

27. Ogembo JG, Kannan L, Ghiran I, Nicholson-Weller A, Finberg RW, Tsokos GC, et al. Human complement receptor type $1 / \mathrm{CD} 35$ is an Epstein-Barr virus receptor. Cell Rep (2013) 3(2):371-85. doi:10.1016/j.celrep.2013.01.023

28. Epstein MA, Morgan AJ, Finerty S, Randle BJ, Kirkwood JK. Protection of cottontop tamarins against Epstein-Barr virus-induced malignant lymphoma by a prototype subunit vaccine. Nature (1985) 318(6043):287-9. doi:10.1038/ $318287 \mathrm{a} 0$

29. Morgan AJ, Mackett M, Finerty S, Arrand JR, Scullion FT, Epstein MA. Recombinant vaccinia virus expressing Epstein-Barr virus glycoprotein gp340 protects cottontop tamarins against $\mathrm{EB}$ virus-induced malignant lymphomas. J Med Virol (1988) 25(2):189-95. doi:10.1002/jmv.1890250209

30. Ragot T, Finerty S, Watkins PE, Perricaudet M, Morgan AJ. Replicationdefective recombinant adenovirus expressing the Epstein-Barr virus (EBV) envelope glycoprotein gp340/220 induces protective immunity against EBVinduced lymphomas in the cottontop tamarin. J Gen Virol (1993) 74(Pt 3): 501-7. doi:10.1099/0022-1317-74-3-501

31. Wilson AD, Shooshstari M, Finerty S, Watkins P, Morgan AJ. Virus-specific cytotoxic $\mathrm{T}$ cell responses are associated with immunity of the cottontop tamarin to Epstein-Barr virus (EBV). Clin Exp Immunol (1996) 103(2):199-205. doi:10.1046/j.1365-2249.1996.d01-607.x
32. Kanekiyo M, Bu W, Joyce MG, Meng G, Whittle JR, Baxa U, et al. Rational design of an Epstein-Barr virus vaccine targeting the receptor-binding site. Cell (2015) 162(5):1090-100. doi:10.1016/j.cell.2015.07.043

33. Gu SY, Huang TM, Ruan L, Miao YH, Lu H, Chu CM, et al. First EBV vaccine trial in humans using recombinant vaccinia virus expressing the major membrane antigen. Dev Biol Stand (1995) 84:171-7.

34. Moutschen M, Leonard P, Sokal EM, Smets F, Haumont M, Mazzu P, et al. Phase I/II studies to evaluate safety and immunogenicity of a recombinant gp 350 Epstein-Barr virus vaccine in healthy adults. Vaccine (2007) 25(24):4697-705. doi:10.1016/j.vaccine.2007.04.008

35. Sokal EM, Hoppenbrouwers K, Vandermeulen C, Moutschen M, Leonard P, Moreels A, et al. Recombinant gp350 vaccine for infectious mononucleosis: a phase 2, randomized, double-blind, placebo-controlled trial to evaluate the safety, immunogenicity, and efficacy of an Epstein-Barr virus vaccine in healthy young adults. J Infect Dis (2007) 196(12):1749-53. doi:10.1086/523813

36. Rees L, Tizard EJ, Morgan AJ, Cubitt WD, Finerty S, Oyewole-Eletu TA, et al. A phase I trial of Epstein-Barr virus gp350 vaccine for children with chronic kidney disease awaiting transplantation. Transplantation (2009) 88(8):1025-9. doi:10.1097/TP.0b013e3181b9d918

37. Czajkowsky DM, Hu J, Shao Z, Pleass RJ. Fc-fusion proteins: new developments and future perspectives. EMBO Mol Med (2012) 4(10):1015-28. doi:10.1002/emmm.201201379

38. Konduru K, Bradfute SB, Jacques J, Manangeeswaran M, Nakamura S, Morshed S, et al. Ebola virus glycoprotein Fc fusion protein confers protection against lethal challenge in vaccinated mice. Vaccine (2011) 29(16):2968-77. doi:10.1016/j.vaccine.2011.01.113

39. Liu H, Saxena A, Sidhu SS, Wu D. Fc engineering for developing therapeutic bispecific antibodies and novel scaffolds. Front Immunol (2017) 8:38. doi:10.3389/fimmu.2017.00038

40. Kontermann RE. Strategies for extended serum half-life of protein therapeutics. Curr Opin Biotechnol (2011) 22(6):868-76. doi:10.1016/j.copbio. 2011.06.012

41. Mekhaiel DN, Czajkowsky DM, Andersen JT, Shi J, El-Faham M, Doenhoff M, et al. Polymeric human $\mathrm{Fc}$-fusion proteins with modified effector functions. Sci Rep (2011) 1:124. doi:10.1038/srep00124

42. Roopenian DC, Akilesh S. FcRn: the neonatal Fc receptor comes of age. Nat Rev Immunol (2007) 7(9):715-25. doi:10.1038/nri2155

43. Hoffman HM, Throne ML, Amar NJ, Sebai M, Kivitz AJ, Kavanaugh A, et al. Efficacy and safety of rilonacept (interleukin-1 Trap) in patients with cryopyrin-associated periodic syndromes: results from two sequential placebo-controlled studies. Arthritis Rheum (2008) 58(8):2443-52. doi:10.1002/ art.23687

44. Boublik Y, Di Bonito P, Jones IM. Eukaryotic virus display: engineering the major surface glycoprotein of the Autographa californica nuclear polyhedrosis virus (AcNPV) for the presentation of foreign proteins on the virus surface. Biotechnology (N Y) (1995) 13(10):1079-84. doi:10.1038/nbt1095-1079

45. Young KA, Chen XS, Holers VM, Hannan JP. Isolating the Epstein-Barr virus gp350/220 binding site on complement receptor type 2 (CR2/CD21). J Biol Chem (2007) 282(50):36614-25. doi:10.1074/jbc.M706324200

46. Chen Q, Cannons JL, Paton JC, Akiba H, Schwartzberg PL, Snapper CM. A novel ICOS-independent, but CD28- and SAP-dependent, pathway of $\mathrm{T}$ cell-dependent, polysaccharide-specific humoral immunity in response to intact Streptococcus pneumoniae versus pneumococcal conjugate vaccine. J Immunol (2008) 181(12):8258-66. doi:10.4049/jimmunol.181.12.8258

47. Ye L, Zeng R, Bai Y, Roopenian DC, Zhu X. Efficient mucosal vaccination mediated by the neonatal Fc receptor. Nat Biotechnol (2011) 29(2):158-63. doi:10.1038/nbt.1742

48. Cairns TM, Huang ZY, Whitbeck JC, Ponce de Leon M, Lou H, Wald A, et al. Dissection of the antibody response against herpes simplex virus glycoproteins in naturally infected humans. J Virol (2014) 88(21):12612-22. doi:10.1128/ JVI.01930-14

49. Whitbeck JC, Huang ZY, Cairns TM, Gallagher JR, Lou H, Ponce-de-Leon M, et al. Repertoire of epitopes recognized by serum IgG from humans vaccinated with herpes simplex virus 2 glycoprotein D. J Virol (2014) 88(14):7786-95. doi:10.1128/JVI.00544-14

50. Wilson AD, Morgan AJ. Indirect measurement of Epstein-Barr virus neutralising antibodies by ELISA. J Virol Methods (1998) 73(1):11-9. doi:10.1016/ S0166-0934(98)00054-8 
51. Sashihara J, Burbelo PD, Savoldo B, Pierson TC, Cohen JI. Human antibody titers to Epstein-Barr virus (EBV) gp350 correlate with neutralization of infectivity better than antibody titers to EBV gp42 using a rapid flow cytometry-based EBV neutralization assay. Virology (2009) 391(2):249-56. doi:10.1016/j.virol.2009.06.013

52. Jegerlehner A, Storni T, Lipowsky G, Schmid M, Pumpens P, Bachmann MF. Regulation of IgG antibody responses by epitope density and CD21-mediated costimulation. Eur J Immunol (2002) 32(11):3305-14. doi:10.1002/1521-4141(200211)32:11<3305::AID-IMMU3305>3.0.CO;2-J

53. Liu W, Chen YH. High epitope density in a single protein molecule significantly enhances antigenicity as well as immunogenicity: a novel strategy for modern vaccine development and a preliminary investigation about B cell discrimination of monomeric proteins. Eur J Immunol (2005) 35(2):505-14. doi:10.1002/eji.200425749

54. Rosenberg AS. Effects of protein aggregates: an immunologic perspective. AAPS J (2006) 8(3):E501-7. doi:10.1208/aapsj080359

55. van Beers MM, Jiskoot W, Schellekens H. On the role of aggregates in the immunogenicity of recombinant human interferon beta in patients with multiple sclerosis. J Interferon Cytokine Res (2010) 30(10):767-75. doi:10.1089/ jir.2010.0086

56. Cui X, Cao Z, Chen Q, Arjunaraja S, Snow AL, Snapper CM. Rabbits immunized with Epstein-Barr virus $\mathrm{gH} / \mathrm{gL}$ or $\mathrm{gB}$ recombinant proteins elicit higher serum virus neutralizing activity than gp350. Vaccine (2016) 34(34):4050-5. doi:10.1016/j.vaccine.2016.06.021

57. Cui X, Cao Z, Sen G, Chattopadhyay G, Fuller DH, Fuller JT, et al. A novel tetrameric gp350 1-470 as a potential Epstein-Barr virus vaccine. Vaccine (2013) 31(30):3039-45. doi:10.1016/j.vaccine.2013.04.071

58. Perez EM, Foley J, Tison T, Silva R, Ogembo JG. Novel Epstein-Barr virus-like particles incorporating gH/gL-EBNA1 or gB-LMP2 induce high neutralizing antibody titers and EBV-specific T-cell responses in immunized mice. Oncotarget (2017) 8(12):19255-73. doi:10.18632/oncotarget.13770
59. Urquiza M, Lopez R, Patino H, Rosas JE, Patarroyo ME. Identification of three gp350/220 regions involved in Epstein-Barr virus invasion of host cells. J Biol Chem (2005) 280(42):35598-605. doi:10.1074/jbc.M504544200

60. Urquiza M, Suarez J, Lopez R, Vega E, Patino H, Garcia J, et al. Identifying gp85-regions involved in Epstein-Barr virus binding to B-lymphocytes. Biochem Biophys Res Commun (2004) 319(1):221-9. doi:10.1016/j. bbrc.2004.04.177

61. Nimmerjahn F, Ravetch JV. Fcgamma receptors as regulators of immune responses. Nat Rev Immunol (2008) 8(1):34-47. doi:10.1038/nri2206

62. Neutra MR, Kozlowski PA. Mucosal vaccines: the promise and the challenge. Nat Rev Immunol (2006) 6(2):148-58. doi:10.1038/nri1777

63. Bornkamm GW, Behrends U, Mautner J. The infectious kiss: newly infected B cells deliver Epstein-Barr virus to epithelial cells. Proc Natl Acad Sci U S A (2006) 103(19):7201-2. doi:10.1073/pnas.0602077103

64. Ogembo JG, Muraswki MR, McGinnes LW, Parcharidou A, Sutiwisesak R, Tison T, et al. A chimeric EBV gp350/220-based VLP replicates the virion B-cell attachment mechanism and elicits long-lasting neutralizing antibodies in mice. J Transl Med (2015) 13:50. doi:10.1186/s12967-015-0415-2

Conflict of Interest Statement: The authors declare that the research was conducted in the absence of any commercial or financial relationships that could be construed as a potential conflict of interest.

Copyright (c) 2018 Zhao, Zhang, Krummenacher, Song, Gao, Zhang, Xu, Feng, Feng, Zeng, Xu and Zeng. This is an open-access article distributed under the terms of the Creative Commons Attribution License (CC BY). The use, distribution or reproduction in other forums is permitted, provided the original author(s) and the copyright owner are credited and that the original publication in this journal is cited, in accordance with accepted academic practice. No use, distribution or reproduction is permitted which does not comply with these terms. 